\title{
On hybrid model for the valuation of credit risk
}

\author{
Fadugba Sunday Emmanuel ${ }^{1, ~ *}$, Edogbanya Olaronke Helen ${ }^{2}$ \\ ${ }^{1}$ Department of Mathematical Sciences, Ekiti State University, Ado Ekiti, Ekiti State, Nigeria \\ ${ }^{2}$ Department of Mathematics, Federal University, Lokoja, Kogi State, Nigeria
}

\section{Email address:}

emmasfad2006@yahoo.com (F. S. Emmanuel),helyna4u@yahoo.com (E. O. Helen)

\section{To cite this article:}

Fadugba Sunday Emmanuel, Edogbanya Olaronke Helen. On Hybrid Model for the Valuation of Credit Risk. Applied and Computational Mathematics. Special Issue: Computational Finance. Vol. 3, No. 6-1, 2014, pp. 8-11. doi: 10.11648/j.acm.s.2014030601.12

\begin{abstract}
This paper presents hybrid model for the valuation of credit risk. Credit risk arises whenever a borrower is expecting to use future cash flows to pay a current debt. It is closely tied to the potential return of investment, the most notable being that the yields on bonds correlate strongly to their perceived credit risk. Hybrid model combines the structural and intensity-based approaches. While avoiding their difficulties, it picks the best features of both approaches; the economic and intuitive appeal of the structural approach and the tractability and empirical fit of the intensity-based approach. In credit derivatives market there are quite a few securities that depend on more than one source of risk, like corporate bonds and convertible bonds, most attractive credit models should involve all these three sources of risk, and interest-rate risk. Our framework brings together these standard block.
\end{abstract}

Keywords: Hazard Rate, Hybrid, Martingale Measure

\section{Introduction}

In recent years, we see a spectacular growth in trading, especially in derivative instruments. There is also an increase complexity of products in the financial markets with the growing complexity and trading size of financial markets, mathematical models have come to play an increasingly important role in financial decision making, especially in the context of pricing and hedging of derivative instruments. Models have become indispensable tools in the development of new financial products and the management of their risks. Credit risk is embedded in a financial transaction and this is the risk that at least one of the parties involved in the transaction will suffer a financial loss due to decline in creditworthiness of the counter-party to the transaction or perhaps of some third party.

Credit risk is closely tied to the potential return of investment, the most notable being that the yields on bonds correlate strongly to their perceived credit risk. The higher the perceived credit risk, the higher the rate of interest those investors will demand for lending their capital. Credit risks are calculated based on the borrower's overall ability to repay. This calculation includes the borrowers collateral assets, revenue generating ability and taxing authority (such as for government and municipal bonds). The default events include a delay in repayments, restructuring of borrower repayments and bankruptcy. Credit risk can be faced by the following:

- $\quad$ Lenders to consumers

- Lenders to business

- $\quad$ Faced by business

- $\quad$ Faced by individuals; like deposit at bank

- Counterpart risk (default risk)

- $\quad$ Sovereign risk (by government).

There are other credit risk valuation methods such as structural model, reduced-form approach etc. Structural models are concerned with modelling and pricing credit risk that is specific to a particular corporate obligor (firm). Credit events are triggered by movements of the firm's value relative to some (random or non-random) creditevent-triggering threshold i.e. the barrier. Consequently, a major issue within this framework is the modelling of the firm's value and of the firm's capital structure. For this reason, the structural approach is frequently referred to as the firm value approach. Through the modelling of credit events in terms of the value of the firm, the structural methodology links the credit events to the firm's economic fundamentals, such as the capital structure of a company. In reduced-form approach, the value of the firm's assets and its capital structure are not modelled at all, and the credit events are specified in terms of some exogenously specified jump process (as a rule, the recovery rates at default are 
also given exogenously). We can distinguish between the reduced-form models that are only concerned with the modelling of default time, and that are henceforth referred to as the intensity-based models, and the reduced form models with migrations between credit rating classes called the credit migration models. The main emphasis in the intensity-based approach is put on the modelling of the random time of default, as well as evaluating condition expectations under a risk-neutral probability of functional of the default time and corresponding cash follows. Typically, the random default time is defined as the jump time of some one-jump process. As well shall see, a pivotal role in evaluating respective conditional expectations is played by the default intensity process. Modelling of the intensity process which is also known as the hazard rate process, is the starting point in the intensity approach.

The first category of credit risk models are the ones based on the original framework developed by R.C. Merton [10]. Using the principles of option pricing developed by $F$ Black and M. Scholes [2]. In such a framework, the default process of a company is driven by the value of the company's assets and the risk of a firm's default is therefore explicitly linked to the variability of the firm's asset value. The basic intuition behind the Merton model is that; default occurs when the value of a firm's assets (the market value of the firm) is lower than that of its liabilities. R.C. Merton [10] derived an explicit formula for risky bonds which can be used both to estimate the probability of default of a firm and to estimate the yield differential between a risk bond and default-free bonds.

One of the major unrealistic assumptions of the original Merton framework was that default can occur only at maturity of the debt when the firm's assets are no longer sufficient to cover debt obligations, but in response to such difficulties, an alternative approach was developed which still adopts the Merton framework as far as the default process is concerned but removed the unrealistic assumptions.

Despite these improvements with respect to the original Merton's framework, the second generation structural-form models still suffer some drawbacks, which represent the main reasons behind their relatively poor empirical performance, one of which is the fact that most structuralform models assume that the value of the firm is continuous in time.

For mathematical background, valuation of credit risk, some numerical method for options valuation and stochastic analysis based on the Ito integral, see ([1], [2], [3], [4], [5], [6], [7], [8], [9], [10], [11], [12], [13], [14], [15]), just to mention a few.

The importance of valuation and hedging models in derivatives markets cannot be over-emphasized. The financial risk can therefore be categorized into four (4) types namely:

- Market risk

- $\quad$ Liquidity risk

- Operational risk
- $\quad$ Credit risk.

In this paper we shall consider hybrid model for the valuation of credit risk only.

\section{Hybrid Model}

This is basically combination of ideas from the structural and intensity based approaches, this is by postulating that the hazard rate of default (intensity) event is directly linked to the current value of the firm's assets (or the firm's equity). Reduced-form models with the specific features are referred to as hybrid model. In this setup, the default time is still a totally inaccessible stopping time, but the likelihood of default may grow rapidly when the total value of the firm's assets approaches some barrier. D.B. Madan and $H$. Unal [9] consider the discounted equity value (including reinvested dividends) process $E_{t}^{*}=E_{t} / B_{t}$ as the unique Markovian state variable in their intensity-based model.

They postulate that the hazard rate of default equals $\lambda_{t}=\lambda\left(E_{t}^{*}, t\right)$ or simply $\lambda_{t}=\lambda\left(E_{t}^{*}\right)$ for some function $\lambda: R_{+} \rightarrow R_{+}$the process $E^{*}$ is assumed to follow a diffusion process, specifically

$$
d E_{t}^{*}=\sigma\left(E_{t}^{*}, t\right) d W_{t}^{*}, E_{t}^{*}>0
$$

Under the martingale measure $p^{*}$ and for some constant volatility coefficient $\sigma$. we assume that the process $E^{*}$ take on strictly positive values: $E_{t}^{*}>0$ for every $t \in[0, T]$. The default time $\tau$ is given by the canonical construction, so that it is defined on an enlarge probability space $(\Omega, G, Q) \cdot W^{*}$ a standard Brownian motion under $Q^{*}$ and $Q^{*}$ is an extension of $p^{*}$.

We take a function

$$
\lambda(x)=c(\ln (x \mid \bar{v}))^{-2}
$$

where $c$ and $\bar{v}$ are strictly positive constants. It is interesting to notice that the stochastic intensity $\lambda_{t}=\lambda\left(E_{t}^{*}\right)$ tends to infinity when the discounted equity value $E_{t}^{*}$ approaches, either from above or from below, the critical level $\bar{v}$.

To avoid making a particular choice of default-free term structure model, we focus on the futures price of a corporate bond.

The futures price $\pi^{f}(X)$ of a contingent claim $X$, for the settlement date $T$, is given by the conditional expectation under the spot martingale measure:

$$
\pi_{t}^{f}(X)=E_{Q^{*}}\left(X \mid G_{t}\right) \text { for } t \in[0, T]
$$

In particular, the futures price $D^{f}(t, T)$ of a default able bond with zero recovery is given by the formula

$$
D^{f}(t . T)=Q^{*}\left\{\tau>T \mid G_{t}\right\}
$$


More explicitly

$$
\left.\begin{array}{rl}
D^{f}(t, T) & =1_{\{T \geq t\}} E_{p^{*}}\left(e^{-\int_{t}^{T} \lambda\left(E_{U}^{*}, u\right) d u \mid} F_{t}\right) \\
& =1_{\{T \geq t\}} V\left(E_{t}^{*}, t\right)
\end{array}\right\}
$$

For some function $v: R_{+} \rightarrow R_{+}$

By virtue of equation (1) and the Feynman-Kao theorem, the function $r$ is satisfies under mild technical assumptions, the following pricing partial differential equation

$$
v_{6}(x, t)+\frac{1}{2} \sigma^{2}(x, t) v_{x x}(x, t)-\lambda(x, t) v(x, t)=0
$$

subject to the terminal condition

$$
v(x, T)=1
$$

For the sake of notational simplicity, we assumed here that $W^{*}$ is one dimensional. Under these assumptions the futures price of a corporate bond is given by

$$
D^{f}(t, T)=G_{v}\left(h\left(E_{t}^{*}, T-t\right)\right)
$$

Where the parameter $v$ satisfies $v(v+1)=2 c \sigma^{-2}$ and

$$
h(x, t)=\frac{2 \sigma^{2} t}{\left(\ln (x \mid \bar{v})-\sigma^{2} t \mid 2\right)^{2}}
$$

For a fixed value of the parameter $v$, the function $G_{v}: R_{+} \rightarrow R$ satisfies the second-order ordinary differential equation

$$
x^{2} G_{v}^{\prime \prime}(x)+\left(\frac{3}{2} x-1\right) G_{v}^{\prime}(x)-\frac{v(v+1)}{4} G_{v}(x)=0
$$

With the initial conditions

$$
\left.\begin{array}{l}
G_{v}^{\prime}(0)=\frac{-V(V+1)}{4} \\
G_{v}(0)=1
\end{array}\right\}
$$

The quasi-explicit valuation formula above may serve to produce estimates of parameters of hazard rate process, based on the observed market yields on default able bonds.

\section{Conclusion}

The risk of loss of principal or loss of a financial reward steaming from borrows failure to repay a loan or otherwise meet a contractual obligation. Credit risk arises whenever a borrower is expecting to use future cash flows to pay a current debt. Investors are compensated for assuming credit risk by way of interest payments from the borrower or issuer of a debt obligation. We conclude this paper by giving few comments on the intensity-based approach to the modeling of credit risk. The advantages and disadvantages listed below are mainly relative to the alternative structural approach. It also worth noting that some of the disadvantages listed below disappears in the hybrid approach to credit risk modeling.

\subsection{Advantages of Hybrid Model}

- The specifications of the value-of-the firm process and the default-triggering barriers are not needed.

- The level of the credit risk is reflected in a simple quantity. The risk-neutral default intensity

- The random time of default is an unpredictable stopping time, and thus the default event comes as an almost total surprise.

- The valuation of default able claims is rather straight forward. It resembles the valuation of default-free contingent claims in term structure models, through well understood techniques.

- Credit spreads are much easier to quantity and manipulate than in structural models of credit risk. Consequently, the credit spreads are more realistic and risk premia are easier to handle.

\subsection{Disadvantages of Hybrid Model}

- Typically, current data regarding the level of the firm's assets and the firm's leverage are not taken into account

- Specific features related to safety covenants and debt's seniority is not easy to handle.

- All (important) issues related to the capital structure of a firm are beyond the scope of this approach.

- Most practical approaches to Portfolio's credit risk are linked to the value-of-the-firm approach.

\section{AMS Subject Classification}

91B30, 91B70, 91G40, 91G80, 91G99

\section{References}

[1] F. Black and J.C. Cox, Valuing Corporate Securities: Some Effects of Bond Indenture Provisions, Journal of Finance, Vol. 31, (1976), 351-367.

[2] F. Black and M. Scholes, The Pricing of Options and Corporate Liabilities Journal of Political Economy, Vol. 81, (1973), 637-654.

[3] M. Crouly, D. Galev, R. Mark, Credit Risk Revisited, RiskCredit Risk Supplement, March, 40-44, (1998).

[4] D. Duffie and K. Singleton, Credit Risk Pricing and Risk Management for Financial Institutions, Princeton University Press, Princeton, (1999).

[5] O. H. Edogbanya and S. E. Fadugba, On Structural Approach for the Valuation of Credit Risk, Journal of Mathematics and System Science, Vol. 4, (2014), 377-386. 
[6] R.J. Elliott and P.E. Kopp, Mathematics of Financial Market, Springer- Verlag, Brelin Heidelberg New York. (1999).

[7] R.J. Elliott, Stochastic Calculus and Applications, SpringerVerlag, Brelin Heidelberg New York, (1982).

[8] S. E. Fadugba and O. H. Edogbanya, On the Valuation of Credit Risk via Reduced-form Approach, Global Journal of Science Frontier Research, Vol. 14, No. 1, Version 1, (2014),49-61.

[9] D.B. Madan and H. Unal, Pricing the Risk of Default, Rev. Derivatives Res, Vol. 2, (1998), 121-160.

[10] R.C. Merton, On the Pricing of Corporate Debt: The Risk structure of Interest Rates, Journal of Finance Vol. 29, (1974), 449-470.

[11] C.R. Nwozo and S.E. Fadugba, Some Numerical Methods for Options Valuation, Communications in Mathematical Finance, Vol.1, No. 1, (2012), 57-74.
[12] S. Titman and W. Torous, Valuing Commercial Mortgages: An Empirical Investigation of the Contigent Claims Approach to Pricing Risky Debt, Journal of Finance, Vol.44, (1989), 345-373

[13] L.A. Weiss, Bankrupty Resolution: Direct Costs and Violations of Priority of Claims, Journal of Financial Econmics, Vol. 27, (1999), 251-272.

[14] L. Yang and H. Zhiqiang, Monte Carlo method for high-tech enterprise IPO market timing: Empirical steady based on American real option approach, International Journal of

[15] Applied Mathematics and Statistics, Vol. 44, (2013), 188195.

[16] Zhigang Wang, Yigui Ou and Baiguang Cai, Option pricing formula for stock model, International Journal of Applied Mathematics and Statistics, Vol. 27, (2012), 49-55. 